\title{
Incorporando histórias: a recomposição do corpo próprio na perspectiva de usuários de serviços de saúde mental
}

\author{
Nuria Malajovich Muñoz ${ }^{* 1}$ \\ Erotildes Maria Lea ${ }^{* 2}$ \\ Catarina Magalhães Dahl*3 \\ Octavio Domont de Serpa Jr.*4
}

\begin{abstract}
O presente estudo acompanha as incidências da experiência de adoecimento na vivência de corpo próprio em pessoas que realizam tratamento em serviços de saúde mental. Por meio de abordagem clínico-qualitativa, interroga-se o papel do cuidado, do ponto de vista dos usuários, em uma possível vivificação da relação com o corpo próprio e sua contribuição na produção de novo modo de existência no cotidiano. Analisam-se as transformações vividas na relação com o corpo e as soluções encontradas para a sua recomposição.
\end{abstract}

Palavras-chave: Corpo, saúde mental, experiência de adoecimento, narrativa

\footnotetext{
${ }^{* 1}$ Universidade Federal Fluminense - UFF (Rio das Ostras, RJ, Br).

*2 Universidade Federal do Rio de Janeiro - UFRJ (Rio de Janeiro, RJ, Br).

${ }^{*}{ }^{3}$ Universidade Federal do Rio de Janeiro - UFRJ (Rio de Janeiro, RJ, Br).

${ }^{* 4}$ Universidade Federal do Rio de Janeiro - UFRJ (Rio de Janeiro, RJ, Br).
} 


\section{SAÚDE MENTAL}

Os efeitos nocivos da rotina institucional imposta pelos hospitais de longa internação foram amplamente denunciados pelo movimento de reforma psiquiátrica. Como assinala Basaglia (2005), a institucionalização do cotidiano em internações psiquiátricas induz à produção de modos de identificação, em que contexto de vida e corpo são tomados exclusivamente como objetos de investigação, de controle e intervenção. Nesta perspectiva o corpo ou se mostra fundido à paisagem do hospital, apresentando-se desvitalizado e transformado em pura instituição desabitada, ou é exibido como último bastião de resistência e está marcado por uma estética que se vale de restos e de dejetos para garantir um traço mínimo qualquer de pessoalidade. A estereotipia do ambiente torna a realidade empobrecida e contribui para o esvaziamento da relação com a linguagem, a palavra não mais operando em sua função conectora entre o sujeito e o mundo. A linguagem é um instrumento importante para o estabelecimento e a manutenção de uma boa distância na relação com os outros (Corin, 2002). Em contrapartida, a desconexão com o seu campo faz da passagem ao ato um horizonte perigoso, a liberação do corpo podendo precipitar o sujeito em queda livre, em uma vertente mortífera e destrutiva.

O campo da saúde mental, opondo-se fortemente ao programa de institucionalização da loucura, procura respostas para o enfrentamento dos problemas vividos por pessoas com transtornos mentais, apostando em novas possibilidades de recuperação. Os serviços territoriais e de base comunitária se esforçam por dar voz aos usuários, que passam a relatar os efeitos negativos da experiência de hospitalização, salientando como a imposição de uma rotina de contornos rígidos e repetitiva reforça a impessoalidade das relações estabelecidas (Vasconcelos, 2006; Karp \& Sisson, 2010). A forma de operar o cuidado em serviços abertos rompe com o modelo tradicional de tratamento, apostando na introdução de pequenas transformações no cotidiano de vida, como meio para a produção 
de formas diferentes de exercer a subjetividade (Golberg, 1998). Incentiva-se a formação de redes afetivas capazes de suportar e acolher diferentes modalidades de ligação com o corpo e com os outros (Leal \& Delgado, 2007).

Blankenburg (1991), importante referência para o estudo do corpo vivido na esquizofrenia, entende a experiência de crise como resultante da ruptura do senso básico de pertencimento ao mundo, uma ausência de familiaridade com o entorno. Pesquisas recentes procuram mapear as vivências corporais de pessoas com transtornos mentais antes de seu aparecimento. Parnas \& Handest (2003) realizam estudo a partir de relatos de pessoas com transtornos psicóticos e apontam que seus testemunhos falam a favor da presença de alterações na apreensão do corpo antes da eclosão da primeira crise psicótica, o que corresponderia a um modo particular de imersão do eu no mundo. Gennart (2011) recorre a vinhetas clínicas e mostra que a presença de fenômenos corporais anteriores ao desencadeamento psicótico sugere um modo especial de relação corpo-mundo, isto é, denota uma condição existencial prévia. Em outra vertente, Klosterkotter (1992) investiga sintomas que antecedem a primeira crise na esquizofrenia, assinalando o aparecimento de sintomas como depressão, fadiga e dificuldade de concentração ou ainda perturbações subjetivas mais sutis em dimensões variadas do funcionamento, como cognição, iniciativa, percepção e nível de energia.

A estranheza em relação ao corpo próprio costuma anteceder a crise psicótica, esta última pondo em evidência, quando de sua eclosão, a preexistência de uma relação alterada com o mundo. Investigar a relação com o corpo introduz, assim, o desafio metodológico de lidar com experiências que costumam ser de difícil tradução. A transposição dessas vivências em termos narrativos implica o manejo de uma dimensão indizível, tornando seu compartilhamento delicado e trabalhoso (Gauthier et al., 2008). É importante destacar ainda que a falta de receptividade social em acolher narrativas que não se inserem no sentido partilhado reforça $o$ isolamento dessas pessoas, aumentando o estigma e conferindo ao sujeito pouca credibilidade (Davidson, 2003). O cotidiano torna-se hostil, aumentando a instabilidade e a desestruturação. Em contrapartida, um enfoque que privilegia e estimula a riqueza narrativa, ou seja, a capacidade de transitar entre diferentes pontos de vista em uma história, encoraja o sujeito a se apropriar de seu cotidiano, impulsionando novas formas de exercer o espaço e de pôr o corpo à obra, aumentando a possibilidade de circulação no meio social (Tranulis et al., 2009).

$\mathrm{O}$ presente estudo acompanha as incidências da experiência de adoecimento na vivência de corpo próprio em pessoas que realizam tratamento em serviços de saúde mental. Por meio de abordagem clínico-qualitativa, analisa-se o material produzido em grupos focais por 18 usuários de Centros de Atenção Psicossocial (CAPS) de três cidades brasileiras (Salvador, Rio de Janeiro e Campinas), explorando a relação com o corpo próprio e o aparecimento dos problemas de saúde 


\section{SAÚDE MENTAL}

mental. Interroga-se o papel do cuidado, do ponto de vista dos usuários, em uma possível vivificação da relação com o corpo próprio e sua contribuição na produção de novo modo de existência no cotidiano. Acompanham-se as transformações que o cuidado produz em uma possível recomposição do sujeito e de seu corpo. Esta pesquisa se insere em um projeto mais amplo, que contou com o apoio financeiro do CNPQ, "Experiência, narrativa e conhecimento: a perspectiva do psiquiatra e a do usuário" (Serpa Jr. et al., 2011; Lopes et al., 2012; Dahl, 2012).

\section{A relação corpo-texto: considerações metodológicas}

A pesquisa voltou-se para a experiência de vida de pessoas que realizam tratamento em CAPS, principalmente no que se refere ao seu processo de adoecimento e de recuperação. As narrativas produzidas em grupos focais foram áudio-gravadas e posteriormente transcritas. Ao acompanhar o fluxo narrativo dos participantes, procuramos situar os meios pelos quais os sujeitos retomam o fio de suas histórias, inserindo-as em contextos específicos. O processo de transcrição da fala dos participantes revelou conexões difíceis de serem percebidas no registro oral. A dispersão da fala se reduziu quando o material áudio-gravado passou para o registro escrito e produziu pistas de orientação. Vale dizer que pessoas com transtornos mentais tendem a descrever suas experiências de modo não usual, exigindo uma abertura discursiva por parte do pesquisador, de modo a tornar possível o acesso a novos universos semânticos (Lysaker e Lysaker, 2008).

Csordas (2008) recorre à teoria semiótica da textualidade para problematizar a relação entre corpo e linguagem e retoma a distinção entre texto e obra proposta por Barthes (2012). Este último, por meio de uma analogia entre textualidade e corporeidade, mostra que a obra remete ao objeto exposto na estante, o livro enquanto produto material; já o texto, a sua vez, demanda um discurso que o ponha em marcha. A experiência corporificada é tomada de modo complementar ao texto enquanto produção discursiva, considerando a primeira como "ponto de partida para analisar a participação humana em um mundo cultural" (Csordas, 2008, p. 368). Isso significa que, embora a cultura tenha propriedades semelhantes ao texto, o paradigma da representação se mostra insuficiente para abarcar a "indeterminação fundamental da existência" (p. 392).

A leitura é o lugar privilegiado de escrita do texto, via pela qual é ressaltado o engajamento do leitor e de seu corpo no processo. Em sua vertente de reescrita, a leitura desperta diferentes dimensões da língua. A leitura não fecha, ela dissemina, produz novas codificações e faz com que o texto não possa ser tomado como produto fechado, mas enquanto campo que pressupõe uma experiência para sua 
produção. A posição do leitor é o de uma figura errante, um vagabundo, caminhante desocupado que passeia por um vale por onde corre um rio, "passeio em diferença que nunca poderá repetir-se senão como diferença” (Barthes, 2012, p. 70).

Considerando o escrito como veículo possível da diferença, Barthes ilumina uma dimensão que tende a ficar oculta em uma primeira abordagem da leitura e que remete à ilegibilidade inerente a todo escrito. Privilegiando aquilo que não se lê, abre a possibilidade de uma não submissão à trava do sentido. Essa manobra não visa ressaltar a polissemia do texto, mas introduzir um modo de leitura que envolve uma travessia, percurso que se articula como plural e irredutível. O leitor é convocado a participar da produção textual, o texto "solicita do leitor uma colaboração prática" (p. 74), o que localiza a leitura do lado de uma prática de escritura. A leitura não remete mais à decifração, mas à produção, amontoado de linguagem, privilegiando assim a leitura "desbussolada" (p. 436), que se deixa afetar pelos rateios da língua, ou seja, pela "sequência de barulhos que um motor dá a entender que está mal regulado" (p. 93) ou pelos seus rumores, enquanto "barulho daquilo que está funcionando bem" (p. 94).

O ponto de vista de Barthes sobre a leitura encontra pontos de aproximação com a abordagem lacaniana da letra. Propomos considerar os rateios da língua, com Lacan (2005), como índice de uma desregulação pulsional. O encontro da palavra com o corpo não produz unidade na psicose, acarreta uma "desordem na junção mais íntima do sentimento de vida no sujeito" (Lacan, 1998, p. 565). A fragmentação da pulsão afeta e despedaça o corpo, causando uma série de dificuldades que envolvem a capacidade de habitar o espaço e até mesmo de nele se locomover. A integridade corporal depende assim da possibilidade de encontrar "uma chave de localização" (Lacan, 1985, p. 230) que oriente o sujeito em seu corpo e no mundo.

A experiência da psicose lança o sujeito em um terreno desconhecido e nunca antes cartografado, exigindo a fabricação de meios particulares para se arranjar com o corpo, com a linguagem e com o mundo. Lacan (1985) mostra que a proliferação alucinatória pode fornecer algumas setas indicadoras, como letreiros que indicam vagamente, à beira dos pequenos caminhos, a direção a seguir. É importante, contudo, frisar que a voz não é o único meio pelo qual a alteridade se faz presente na psicose, "existem outras vias que não as vocais para receber a linguagem" (Lacan, 2005, p. 299). Embora a voz alucinada seja uma modalidade de retorno que mobiliza a escuta, outras funções podem ser perturbadas, como a visão, a sensação ou ainda a leitura. Segundo as diferentes modalidades de retorno, partes específicas do corpo ganham destaque, em uma conformação estranha e imprecisa.

A vivência do fora-do-espaço, ou seja, o aparecimento de uma extraterritorialidade radical impõe o desafio de pôr em marcha um corpo cuja relação experimentada é, com frequência, de desapossamento (Lacan, 2005, p. 135). O terreno pode ficar povoado de folhas mortas, tornando o caminhar incerto (p. 275) ou, em 


\section{SAÚDE MENTAL}

um sentido inverso, induzindo o sujeito a errar sem fim na encruzilhada (Lacan, 1985, p. 329). Resta então saber como alguns sujeitos conseguem ligar os pontos da malha, pinçar entre determinados elementos da rede e construir a passagem de um ponto a outro até estabelecer uma rota, restituindo a circulação.

O último ensino de Lacan aponta um modo de estabilização que não implica uma restituição de sentido por meio do trabalho delirante, tal como proposto por Freud (1989) em seu caso Schreber. O fato da linguagem não obedecer, na psicose, à estrutura metafórica, deixa o sujeito à mercê de constantes quebras semânticas. A escrita, entendida como escritura, é um artifício capaz de articular os restos da língua que requisitam o corpo. Tomada, nesse sentido, como "fazer que dá suporte ao pensamento" (Lacan, 2007, p. 140), a escrita inaugura um saber fazer com aquilo que se desregula na psicose. Embora as significações produzidas em uma narrativa não possam ser desconsideradas, o foco incide no potencial da letra em fazer-se instrumento para acomodar aquilo que escapa ao sentido (Laurent, 1995).

As teorizações sobre a letra permitem acentuar a dimensão corporal da escrita, presença daquilo que está para além de toda significação. $\mathrm{O}$ texto, ao incluir a produção de uma borda, delimita um espaço vazio, condição de escoamento daquilo que é vivido como excesso no corpo. O tratamento da letra requer a invenção, por parte de cada sujeito, de instrumentos de orientação, composição própria feita de restos e peças avulsas. Em um processo de escritura, marcas vão se formando como reentrâncias deixadas pela passagem da água em um terreno (Lacan, 2003). A prática da letra demarca uma distância entre o espaço literal e corpo e se apresenta por isso como uma possibilidade de suporte para o trabalho clínico com a psicose (Castello Branco, 1997). Vale lembrar que os múltiplos caminhos traçados durante o estabelecimento de um texto desaparecem em sua versão final. Isso não torna, entretanto, o processo de escritura menos importante do que o texto propriamente dito, determinando inclusive sua condição de existência.

\section{Ruínas do corpo, garimpo no texto}

A produção textual dos participantes da pesquisa nos aproxima de um território composto de elementos singulares, percurso cujo movimento dá a ver o exercício cotidiano de conquista e recomposição do corpo próprio. A aproximação da experiência que antecede o adoecimento se dá por meio de um recurso narrativo peculiar. As considerações iniciais são povoadas de múltiplas referências a nomes de ruas, bairros, escolas, empresas, centros religiosos, linhas de ônibus. Essas balizas espaciais parecem ter um papel importante na sustentação do curso narrativo, ajudando os participantes a situarem-se na história que começa a ser 
contada. A partir de alguns elementos-chave, uma cartografia espacial/afetiva do vivido subjetivo é estabelecida. O resgate e a sinalização de pequenos pontos de referência auxiliam na localização subjetiva, servindo de ponto de apoio para a sustentação da história biográfica. Destacamos, a seguir, passagens extraídas das narrativas nas quais se localiza esse tipo de manobra. Por questões de sigilo, os nomes próprios foram substituídos por nomes fictícios.

“(...) eu fiquei doente. E aí, o que me levou a pensar nisso tudo quando era moleque, eu tinha 15 anos quando era morador da Cruz Vermelha... E quando estava morando lá em Afonso Miranda. (...) pra Cohab, porque eu morava ali naqueles apartamentos da Cohab, ali em Afonso Miranda (...) Ai eu fui morar.. eu me mudei para Jardim Guanabara... Aí eu saí do centro, em Afonso Miranda”. (Rui)

“(...) eu estudava também... eu estudei na primeira escola, o primário do... perto do trevo de Júlio Saldanha depois eu estudei na terceira escola Estadual... não sei se era segundo grau, é... depois eu estudei no João Ferreira... de Pedrosa e depois não sei se foi Júlio de Macedo, Juana Pires de Albuquerque... porque Juscelino eu não trabalhei, num estudei... (...) acho que era uma escola que tinha... que a minha irmã caçula estudou, eu tinha que passar lá.. pra levar ela embora... e... Juana Pires de Albuquerque eu estudei e Júlio de Macedo aqui eu estudei naquela escola ali”. (Cícero)

É interessante observar que o recurso à nomeação parece dar corpo à narrativa que se desenrola a partir dessas múltiplas referências. Os nomes próprios, utilizados como sinalizações, orientam e encorajam o narrador a se apropriar de seus fragmentos de memória, fios que remendam as lacunas de uma história profundamente abalada pelo adoecimento. A estratégia revela um modo peculiar de estabelecer relações e de dar corpo a uma história. É importante dizer que a nomeação se caracteriza por um processo linguístico que apresenta uma dimensão mais literal do que a produção de sentido, ou seja, demarca um campo para além da significação.

A experiência do adoecimento insere-se em um longo processo que marca o corpo e que não conta com o discurso corrente como maneira eficaz para descrever os fenômenos em jogo. Nesse sentido, nomear a experiência ou pelo menos bordejar os seus contornos constitui-se como recurso interessante para situar o indizível, as palavras podendo servir como apoio na tradução de vivências que estão radicalmente fora do sentido partilhado. A produção narrativa cria caminhos e novas possibilidades de transitar na linguagem, reconstruindo a paisagem abalada pela experiência da crise.

Um recurso semelhante é adotado pelos sujeitos na descrição de experiências corporais ligadas ao início do adoecimento, esforçando-se em realizar seu 


\section{SAÚDE MENTAL}

mapeamento. O corpo se apresenta como massa amorfa, território desconhecido a ser cartografado.

"Tem um sentimento mal, né? A pessoa não se sente bem. Então, vem a taquicardia, a taquicardia é derivada do momento de disparadas do coração, ora ele para ora ele avança. Dor de cabeça... dor de cabeça, né? Uma forte dor de cabeça... Inflamação... Inflamação do sistema nervoso. Geralmente do sistema nervoso". (César)

"Os músculos da minha face estavam contraídos, eu tentava sorrir e não conseguia. (...) A gente sente uma dor sem ter nada, sem ter machucadura nenhuma". (Sonia)

"Uma pressão que sobe no corpo... uma pressão que me alterou muito violentamente, entende (...). Subiu um... pelo coração, cérebro, a maior parte do corpo”. (Rogério)

Algumas narrativas referem, antes da primeira crise, um desconforto difuso que se manifesta na realização de atividades cotidianas, antes consideradas rotineiras. "Eu chegava em casa não conseguia dormir, dormia duas horas, três horas. Eu acho que o começo da minha doença foi ai" (Ricardo). Pode ainda se apresentar como uma experiência sutil: "Você vai tendo uma espécie de crise existencial, uma angústia, uma falta de alegria que você não sabe direito o que é" (Reinaldo). O corpo se torna sujeito a explanações, servindo de palco para hipóteses e teorias explicativas sobre o adoecimento. "Eu acho que é por força de uma desnutrição. Algum tipo de vitamina, proteína que me deixava com essa variação na ideia. (Saulo). "Eu tenho o ouvido aberto. Jogando bola com meu irmão, eu caí e bati o ouvido no meio-fio. Agora que eu vim descobrir que as pessoas ouvem vozes de mim por causa do meu ouvido aberto" (Sílvio). Outros participantes experimentam a eclosão da primeira crise como uma descontinuidade, quebra que altera radicalmente a relação com o corpo. "Eu tinha uma segurança muito grande (...) a crise me deixou desarmada" (Sonia). "Me sentia normal [com a crise] (...) você perde os cinco sentidos, os cinco sentidos vão pra falência" (César).

Podemos medir a dificuldade e o esforço que os usuários precisam empreender para demarcar uma distância na relação eu-mundo, recorrendo para isso a um trabalho de localização das transformações que alteram o corpo em sua capacidade de se afetar e de reagir. As alterações podem ser sutis e envolver registros variados da experiência, como se exemplifica no relato de um dos participantes que descreve a vivência de estranhamento em relação à atividade de leitura, mais especificamente na articulação escrita/leitura: 
"Eu pegava uma folha (...) e assim... eu passava o olho (...) eu não me restringia só ali ao que tá escrito. O espaço em branco, eu queria ver de perto o espaço em branco, o meu olho, para ver se tinha alguma outra escrita. Ao mesmo tempo em que eu sabia que não tinha, que era coisa da minha cabeça - eu caía nesse transtorno”. (Raílson)

O desencadeamento da crise deixa o corpo vulnerável e exposto, colapsando as fronteiras eu-mundo e introduzindo uma presença sentida como profundamente invasiva. Um desajuste radical atinge o corpo desde fora e altera sua ligação ao mundo, lançando o sujeito em um sentimento de solidão radical, de não pertencimento. " $A s$ vozes começam muito forte” (Roberta). "Quando eu vim pra cá (...) ainda estava muito alucinado... e escutando vozes, (...) perturbado” (Ricardo). A experiência de ouvir vozes modifica definitivamente a relação com o cotidiano e vem corporificar essa presença que tende a ser considerada como marca indelével de adoecimento.

Uma série de desarranjos, produzidos na relação com o corpo próprio, tornam o cotidiano penoso e problemático. Os usuários indicam que a prevalência de uma posição de objeto de intervenções e manipulações deixa pouco espaço para uma possível percepção de melhora ou perspectiva de recuperação. A medicação introduz efeitos desagradáveis como alterações na imagem e na forma do corpo. "Minha medicação foi dobrada, tudo. (...) Ganhei muita massa corporal, engordei bastante” (Regina). Pode ainda requerer o cumprimento de uma rotina dolorosa:

"Eu tomo injeção e remédio sabe... muita injeção que eu tomo, mais de duas mil injeção, né, não é fácil não, tô sofrendo, muita injeção na vida... duas mil injeção e ... muito remédio, remediada que eu tomo ai... tomar um monte de agulhada, não é fácil não, tomar um monte de agulhada... agulhada não, dói... sofri, sofri..." (Caio)

\section{A recomposição do corpo e o convívio no CAPS}

A oferta de um serviço aberto e em articulação com o contexto vivido pode, no que se refere à experiência dos usuários, auxiliar na conquista do corpo e na procura de novos modos de exercer a subjetividade? Em relação à medicação, o CAPS parece introduzir outro modo de abordagem quando comparada à internação psiquiátrica, onde a prescrição medicamentosa costuma ser imposta e não negociada. Contrariamente à experiência da internação, a medicação se insere no dispositivo CAPS em uma gama de ofertas mais ampla e não como imposição arbitrária. "No sanatório você é obrigado a tomar medicação, você não tem querer. No 


\section{SAÚDE MENTAL}

CAPS, você pega o medicamento leva pra casa, tem o domínio, o controle" (Saulo). O tratamento realizado no CAPS é considerado como fator importante na recuperação, oferta de um cotidiano estável que ajuda a se mover, a participar de um espaço de troca e a realizar atividades variadas. "O remédio, as oficinas, a companhia da [técnica de referência], dos amigos, batendo papo, os passeios (...). Então aqui é bom por isso [porque não é uma prisão]. A gente vai embora sozinho. Vem sozinho, tem amigos pra conversar" (Silvio). A inércia é vista como principal sinal de adoecimento, fala-se muito da necessidade de movimento, de empreender alguma atividade que faça o corpo se mexer. "Tem que brigar consigo mesmo, brigar com a doença, pra não ficar assim jogada" (Selma). "Tem que cuidar do corpo se não a mente fica só fechada em casa" (Caio). As narrativas apontam ainda a importância de pequenas conquistas na vida diária. "Eu me sinto muito bem, porque hoje eu pego ônibus e venho sozinha (...) eu não andava sozinha mais, você entende? Eu não descia o morro para ir na padaria. Hoje eu vou na padaria, hoje eu vou no mercado" (Roberta).

\section{Considerações finais}

A circulação e a capacidade de transitar pelo mundo figuram entre as categorias utilizadas pelos participantes para sinalizar indícios importantes de restabelecimento, processo de reconquista do corpo e do sentimento de si. As narrativas mostram a importância de encontrar um modo de se virar com o corpo e com a linguagem, em detrimento de um saber explicativo. Não se trata tanto de atribuir sentido ao adoecimento, mas de conquistar um novo sentimento de si a partir de estratégias de habitar o corpo.

As alterações no sentimento de si exigem a convivência com uma alteridade radical e com o retorno do vivido em um registro inesperado, provocando uma espacialização da subjetividade que requisita a invenção de novos modos de pensar o corpo e seus limites. A aposta na palavra não visa à produção de significados sobre o processo experimentado, mas retraça a experiência cotidiana no ato mesmo de contar uma história, prática que destaca as soluções encontradas para se ancorar ao corpo. Esse procedimento valoriza o hábito enquanto "modo de conhecimento e intervenção radicado no corpo" (Rabelo et al., 1999, p. 13), priorizando um modo de fazer adquirido no exercício prático da vida. A prática narrativa promove uma abertura, acesso que informa sobre a língua do outro, dando novo colorido aos pequenos assuntos, às banalidades, aos costumes e às práticas corriqueiras (Miller et. al., 2003). O cotidiano se constrói tendo em vista aquilo que faz articulação para cada um, dobradiça que permite conectar-se ao mundo de vida. Essa visada confere novo estatuto ao saber fazer em detrimento da produção de saber inconsciente (Miller, 1997). 
Corpo e narrativa se entrelaçam na experiência cotidiana: o processo narrativo engaja o corpo. O convite a tomar a palavra requisita o corpo, gera efeitos que o tocam e o afetam. Por outro lado, a narrativa produz um corpo, na medida em que envolve a confecção de um objeto, a produção textual. $\mathrm{O}$ traçado que se realiza ao contar uma história delimita um espaço singular que marca um contorno e confere um lugar ao sujeito da narrativa. Viabilizar novos arranjos linguísticos e validar a descrição de experiências que não respondem ao modo costumeiro de organização do conteúdo de uma história é fundamental para dar corpo à experiência da psicose. $\mathrm{O}$ desafio consiste em conferir um lugar para aquilo que não pode ser absorvido pela linguagem em termos representacionais. Essa manobra privilegia um tipo de leitura que não descarta o que está fora do sentido, possibilitando que este tenha um lugar e possa vir a se acomodar no texto.

As narrativas revelam que o CAPS desempenha um papel importante na busca empreendida pelos usuários por modos de habitar o corpo e a linguagem após a crise. Embora esta última torne a realidade confusa e invasiva, os usuários sugerem ser possível desenvolver meios e truques para entrepor uma distância na relação com os outros. A abertura discursiva, por parte do interlocutor, é fundamental para a validação de novos caminhos, fazendo surgir, na periferia do texto, referências fora das convenções da norma, lugar inexplorado que pode proteger das injunções sociais, viabilizando a retomada do movimento e da circulação. Ao incluir o CAPS em um circuito que engaja o corpo, os usuários acentuam o caráter corporificado da experiência humana. Frequentar o serviço contribui para o aumento da capacidade de circulação, facilita o ir e vir e o trânsito pela cidade. As narrativas valorizam esse aspecto e mostram que as mazelas do corpo perdem potência à medida que ganha espaço a experiência do corpo em ação.

\section{Referências}

Barthes, R. (2012). O rumor da lingua. São Paulo: Martins Fontes.

Basaglia, F. (2005). Corpo e instituição: considerações psicopatológicas e antropológicas em psiquiatria institucional. In Escritos selecionados em Saúde Mental e Reforma Psiquiátrica. Rio de Janeiro: Garamond.

Blankenburg, W. (1991). La perte de l'evidence naturelle. Paris: PUF.

Castello Branco, L. (1997). Palavra em ponto de p. In P. de Andrade \& S. A. Silva (Orgs.). Um corp'a screver. Belo Horizonte, FALE/UFMG.

Corin, E. (2002). Se rétablir après une crise psychotique: ouvrir une voie? Retrouver sa voix? Revue Santé Mentale au Québec, 27(1), 65-822. 


\section{SAÚDE MENTAL}

Csordas, T. (2008). Corpo/ significado/ cura. Porto Alegre: Editora da UFRGS.

Dahl, C. M. (2012). Experiência, narrativa e intersubjetividade: o processo de restabelecimento (recovery) na perspectiva de pessoas com diagnóstico de esquizofrenia em tratamento nos centros de atenção psicossocial. Dissertação de mestrado. Universidade Estadual de Campinas - Unicamp.

Davidson, L. (2003). Living outside Mental Illness: qualitative studies of recovery in schizophrenia. New York: University Press.

Freud, S. (1989). Notas psicanalíticas sobre um relato autobiográfico de um caso de paranoia. In Edição Standard Brasileira das Obras Psicológicas Completas de Sigmund Freud (Vol. XII). Rio de Janeiro: Imago. (Trabalho original publicado em 1911).

Gauthier, A. et al. (2008, oct./dec.). Au-delà des modèles de pratique: explorer la rencontre clinique en début de psychose. L'évolution psychiatrique, 73(4), 639-654.

Gennart, M. (2011). Corporéité et presence: jalons pour une approche du corps dans la psychose. Argenteuil: Le cercle herméneutique editeur.

Goldberg, J. (1998). Cotidiano e instituição: revendo o tratamento de pessoas com transtorno mental em instituições públicas. Tese de doutorado em Medicina Preventiva. Universidade de São Paulo.

Karp, D. A. \& Sisson, G. E. (2010). Voices from the inside: readings on the experience of mental illness. Oxford: Oxford University Press.

Klosterkotter, J. (1992). The meaning of basic symptoms for the genesis of the schizophrenic nuclear syndrome. The Japanese Journal of Psychiatry and Neurology, 46(3), 609-630.

Lacan, J. (1985). O seminário. Livro 3. As psicoses. Rio de Janeiro: Jorge Zahar. (Trabalho original publicado em 1955-1956).

Lacan, J. (1998). De uma questão preliminar a todo tratamento possível das psicoses. In: Escritos. Rio de Janeiro: Jorge Zahar. (Trabalho original publicado em 1957-1958).

Lacan, J. (2005). O seminário. Livro 10. A angústia. Rio de Janeiro: Jorge Zahar. (Trabalho original publicado em 1962-1963).

Lacan, J. (2007). O seminário. Livro 23. O sinthoma. Rio de Janeiro: Jorge Zahar. (Trabalho original publicado em 1975-1976).

Lacan, J. (2003). Lituraterra. In Outros escritos. Rio de Janeiro: Jorge Zahar. (Trabalho original publicado em 1971).

Laurent, E. (1995). O psicótico escreve. In Versões da clínica psicanalítica (pp. 167-175). Rio de Janeiro: Jorge Zahar.

Leal, E. M. \& Delgado, P. G. G. (2007). Clínica e cotidiano: o CAPS como dispositivo de desinstitucionalização. In R. Pinheiro et al. (Org.). Desinstitucionalização na saúde mental: contribuições para estudos avaliativos (pp. 137-154). Rio de Janeiro: CEPESC: IMS/ LAPPIS, ABRASCO.

Lopes, T. et al. (2012). O processo de restabelecimento na perspectiva de pessoas com diagnóstico de transtornos do espectro esquizofrênico e de psiquiatras na rede pública de atenção psicossocial. Saúde e Sociedade (USP. Impresso), 21, 558-571. 
Lysaker, P. \& Lysaker, J. (2008). Schizophrenia and the Fate of the Self. Oxford: Oxford University Press.

Miller, J-A. (1997). La conversation d'Arcachon. Cas rares: les inclassables de la clinique. Paris: Seuil.

Miller, J.-A. et al. (2003). La psicosis ordinária. Buenos Aires: Paidós.

Parnas, J. \& Handest, P. (2003, Mar/Apr.). Phenomenology of Anomalous Self-Experience in Early Schizophrenia. Comprehensive Psychiatry, 44(2), 121-134.

Rabelo, M. C. et al. (1999). Experiência de doença e narrativa. Rio de Janeiro: Editora Fiocruz.

Serpa Jr., O. D. et al. (2011). Experiência, narrativa e conhecimento: a perspectiva do psiquiatra e a do usuário. Relatório final de pesquisa aprovado pelo $\mathrm{CNPq}$ através do edital MCT/ CNPq/MS/SCTIE/DECIT n ${ }^{\circ}$ 033/2008, Processo 575257/2008-3 (mimeo).

Tranulis, C. et al. (2009). Narrative insight: rethinking insight in psychosis. International Journal of Culture and mental Health, 2(1), 16-28.

Vasconcelos, E. M. (Org.). (2006). Reinventando a vida: narrativas de recuperação e convivência com o transtorno mental. São Paulo: Hucitec.

\section{Resumos} service)

(Incorporating stories: recomposing the body from the perspective of users health

This study is about experiences of physical illness in persons treated at public mental health clinics. Through a qualitative clinical approach the role of care is questioned from the users' point of view in a possible participation in the relationship with their own bodies and its contribution in producing new ways of existence in everyday life. We analyze the changes experienced in relationships with the users'own bodies and solutions found for recomposing it.

Key words: Body, mental health, experience of illness, narrative

(L'incorporation d'histoires: la recomposition du corps propre dans la perspective des usagers de services de santé mentale)

Cette étude accompagne l'expérience de la maladie et de ses effets sur le corps de patients qui suivent un traitement dans un service de santé mentale. À l'aide d'une approche clinique qualitative, nous étudions le rôle des soins du point de vue des usagers, dans une possible recomposition du rapport avec le corps, ainsi que sa contribution à la production d'un nouveau mode d'existence dans la vie quotidienne. Nous abordons les transformations qui résultent du rapport avec le corps et les solutions qui visent sa reconstruction.

Mots clés: Corps, santé mentale, expérience de la maladie, narrative 


\section{SAÚDE MENTAL}

(Incorporando historias: la recuperación del cuerpo en la perspectiva de usuarios de servicios de salud mental)

Este estudio analisa el efecto de la experiencia de enfermarse en la vivencia del propio cuerpo en personas que reciben tratamiento en servicios de salud mental. A través de un enfoque clínico-cualitativo, cuestionamos el papel del cuidado en la visión de los usuarios, en una posible vivificación de la relación con el propio cuerpo y su contribución en la producción de um nuevo modo de existencia en la vida cotidiana. Se analizan las transformaciones vividas en la relación con el cuerpo y las soluciones encontradas para su recomposición.

Palabras clave: Cuerpo, salud mental, experiencia de enfermedad, narrativa

(Verkörperung von Geschichten: die Umbildung des eigenen Körpers aus der Perspektive der Nutzer von Diensten des Gesundheitswesens für psychisch Kranke)

In dieser Untersuchung werden die Auswirkungen an den Menschen begleitet, die das Krankwerden am eigenen Körper erfahren und sich Behandlungen des Gesundheitswesens für psychisch Kranke unterziehen. Durch den klinisch qualitativen Ansatz wird die Rolle der Betreuung in einer möglichen neuen Erfahrung mit dem eigenen Körper aus der Sicht der Patienten hinterfragt, sowie sein Beitrag zur Gestaltung einer neuen Art der Existenz im Alltag. Es wird weiterhin untersucht welche Verwandlungen dieser Mensch in Bezug auf seinen Körper erlebt und welche Lösungen zu seiner Umbildung gefunden wurden.

Schlüsselwörter: Körper, geistige Gesundheit, Erfahrung des Krankwerdens, berichten

Citação/Citation: Muñoz, N. M.; Leal, E. M.; Dahl, C. M. \& Serpa Jr., O. D. de (2014, dezembro). Incorporando histórias: a recomposição do corpo próprio na perspectiva de usuários de serviços de saúde mental. Revista Latinoamericana de Psicopatologia Fundamental, 17(4), 872-886.

Editor do artigo/Editor: Profa. Dra. Ana Cristina Costa de Figueiredo e Profa. Dra. Andrea Máris Campos Guerra

Recebido/Received: 4.12.2013/ 12.4.2013 Aceito/Accepted: 20.1.2014/ 1.20.2014

Copyright: (C) 2009 Associação Universitária de Pesquisa em Psicopatologia Fundamental/ University Association for Research in Fundamental Psychopathology. Este é um artigo de livre acesso, que permite uso irrestrito, distribuição e reprodução em qualquer meio, desde que o autor e a fonte sejam citados / This is an open-access article, which permits unrestricted use, distribution, and reproduction in any medium, provided the original authors and sources are credited. 
Financiamento/Funding: A pesquisa foi financiada pelo Conselho Nacional de Desenvolvimento Científico e Tecnológico - CNPq / The research was funded by the Conselho Nacional de Desenvolvimento Científico e Tecnológico - CNPq.

Conflito de interesses/Conflict of interest: Os autores declaram que não há conflito de interesses / The authors have no conflict of interest to declare.

\section{Nuria Malajovich Muñoz}

Doutora em Teoria Psicanalítica pela Universidade Federal do Rio de Janeiro - UFRJ (Rio de Janeiro, RJ. Br); Professora Adjunta da Universidade Federal Fluminense, Polo Universitário de Rio das Ostras; Pesquisadora do Laboratório de Estudos e Pesquisas em Psicopatologia e Subjetividade IPUB/UFRJ (Rio de Janeiro, RJ, Br).

Rua General Glicério, 326/603 - Laranjeiras

22245-120 Rio de Janeiro, RJ, Br.

e-mail: nuriamalajovich@gmail.com

\section{Erotildes Maria Leal}

Doutora em Ciências da Saúde pela Universidade Federal do Rio de Janeiro - UFRJ (Rio de Janeiro, RJ, Br); Pós-doutora pela Universidade de Toronto/CICAD; Professora Adjunta da Universidade Federal do Rio de Janeiro; Professora Associada da Pós-graduação em Saúde Coletiva da Faculdade de Ciências Médicas da Universidade Estadual de Campinas - Unicamp (Campinas, SP, Br); Pesquisadora do Laboratório de Estudos e Pesquisas em Psicopatologia e Subjetividade IPUB/UFRJ (Rio de Janeiro, RJ, Br).

Rua Capitão Salomão, 68/703 - Botafogo

22271-040 Rio de Janeiro, RJ, Br.

e-mail:erotildesleal@macae.ufrj.br

\section{Catarina Magalhães Dahl}

Mestre em Saúde Coletiva pela Universidade Estadual de Campinas - Unicamp (Campinas, SP, Br); Pesquisadora do Laboratório de Estudos e Pesquisa em Psicopatologia e Subjetividade, Instituto de Psiquiatria da Universidade Federal do Rio de Janeiro - IPUB/ UFRJ (Rio de Janeiro, RJ, Br).

Rua Aarão Reis, 102 casa - Santa Tereza

20240-090 Rio de Janeiro, RJ, Br.

e-mail: catdah178@gmail.com

\section{Octavio Domont de Serpa JR}

Doutor em Psiquiatria e Saúde Mental pela Universidade Federal do Rio de Janeiro - UFRJ (Rio de Janeiro, RJ, Br); Pós-doutor pelo Centre de Recherches en Epistémologie Apliquée/ Ecole Polytechnique - Paris; Professor Adjunto da Universidade Federal do Rio de Janeiro e coordenador do Laboratório de Estudos e Pesquisas em Psicopatologia e Subjetividade IPUB/UFRJ (Rio de Janeiro, RJ, Br).

Av. Ataulfo de Paiva, 983/203 - Leblon

22440-034 Rio de Janeiro, RJ, Br

e-mail: domserpa@gmail.com 